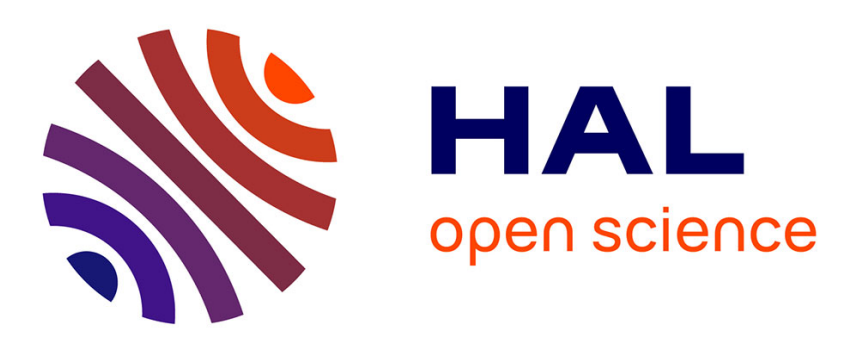

\title{
In situ community dynamics influences the temperature- and light- dependent succession of seasonal phytoplankton
}

Margot Tragin, Stefan Lambert, Jean-Claude Lozano, François-Yves Bouget

\section{- To cite this version:}

Margot Tragin, Stefan Lambert, Jean-Claude Lozano, François-Yves Bouget. In situ community dynamics influences the temperature- and light- dependent succession of seasonal phytoplankton. 2021. hal-03436983

\section{HAL Id: hal-03436983 https://hal.science/hal-03436983}

Preprint submitted on 19 Nov 2021

HAL is a multi-disciplinary open access archive for the deposit and dissemination of scientific research documents, whether they are published or not. The documents may come from teaching and research institutions in France or abroad, or from public or private research centers.
L'archive ouverte pluridisciplinaire HAL, est destinée au dépôt et à la diffusion de documents scientifiques de niveau recherche, publiés ou non, émanant des établissements d'enseignement et de recherche français ou étrangers, des laboratoires publics ou privés. 
1 In situ community dynamics influences the temperature- and light- dependent

\section{succession of seasonal phytoplankton}

3 Margot $\operatorname{Tragin}^{1}$, Stefan Lambert ${ }^{1}$, Jean-Claude Lozano ${ }^{1}$, François-Yves Bouget ${ }^{1,2}$

$4 \quad{ }^{1}$ Sorbonne Université, CNRS, UMR7621, Laboratory of Microbial Oceanography, Observatoire

5 Océanologique, Avenue Pierre Fabre, 66650 Banyuls sur mer, France

$6 \quad{ }^{2}$ Corresponding author: fy.bouget@obs-banyuls.fr

7

\section{Compliance with ethical standards}

9 The authors declare that they have no conflict of interest. 


\section{Abstract}

Temperature and light play a crucial role in regulating phytoplankton blooms in the

13 Ocean. To assess the importance of these two parameters experimentally, microcosms were

14 conducted on seven picoplankton communities $(<3 \mu \mathrm{m})$ sampled in December, March, June and

15 September 2015 and 2016 in the North Western Mediterranean Sea. Each community was

16 exposed to 4 realistic seasonal conditions (December, March, June and September).

17 Metabarcoding was used to investigate the eukaryotic diversity in the 56 microcosms experiments in parallel to high-frequency monitoring of environmental diversity in the sea. The three major lineages identified were the Stramenopiles, Alveolata and Archaeplastida. Overall, the five-day incubations were not sufficient to reshape the initial microbial communities completely. The microcosm outcome was strongly influenced by the dynamics of phytoplankton starting communities. In pre-bloom conditions, phytoplanktonic species were the most sensitive to temperature and light conditions. During a bloom, species belonging to diatoms or

24 Chlorodendrophyceae usually did not respond to light and temperature in microcosms and continued to bloom independently of the applied seasonal condition. Together, these results suggest that light and temperature seasonal conditions play a crucial role in regulating phytoplankton dynamics in pre-bloom conditions and biotic interactions may be preponderant in bloom and post-bloom conditions.

\section{Keywords}

Phytoplankton, seasonality, light, temperature, microcosms, metabarcoding, Mamiellophyceae,

31 Chlorodendrophyceae, diatoms. 


\section{Introduction}

As soon as marine planktonic life was discovered in the late XIX century, several studies reported phenology of plankton abundance [1]. The organisms size, whose seasonal pattern were described, evolved together with improvements of detection methods, from light microscopy to molecular techniques. The annual temporality of zooplankton such as copepods and large size phytoplankton such as diatoms and dinoflagellates has been studied for over a century in Northern Mediterranean Sea waters [1-5]. Later, small size picophytoplankton (cell size $<3 \mu \mathrm{m}$ ), such as the green picoalga Micromonas sp. were found to seasonally grow also in the Mediterranean sea $[6,7]$. In the nineties, extensive microscopy-based taxonomic survey reported that photosynthetic dinoflagellates and diatoms had strong seasonal patterns in NW Mediterranean Sea coastal waters and described sequential phytoplankton spring blooms in the bay of Villefranche sur Mer (France): diatoms blooming in late spring and autumn while dinoflagellates being more abundant in summer [8]. More recently, the development of molecular analyses and high throughput sequencing enabled the tracking of all planktonic organisms' temporal distribution, including the picoplankton [9]. In recent years, the development of molecular analyses and high throughput sequencing allowed the extensive monitoring at an unprecedented taxonomic level, the temporal succession of all planktonic organisms including the smallest protists (i.e., picoplankton cell size $<3 \mu \mathrm{m}$ ).

A time series metabarcoding approach conducted in the bay of Banyuls sur Mer (North Western Mediterranean Sea, France) over seven years revealed a strong temporal factor driving the biogeography of dinoflagellates and pico-sized green alga (Chlorophyta) belonging to the Mamiellophyceae class (Bathycoccus and Micromonas) [9, 10]. A quarter of photosynthetic reads were commonly assigned to Chlorophyta using 18 S rRNA metabarcoding, describing panoceanic datasets [11]. The beginning of bloom events appears to be predictable by mathematical models that combine both nutrients, temperature and light parameters with hydrodynamics 
factors [12]. In situ high frequency sampling also unveiled the importance of daily variations in wind or rain on microbial community structures [13]. In addition to meteorological events, hydrographic modifications of environmental factors, which are thought to drive the seasonality of plankton, biotic interactions such as parasitism [14] were assumed to be influencing the end of blooming dynamics in marine waters [15]. experimentally. Methodological approaches are not standardized regarding parameters such as temperature, nutrients or $\mathrm{pH}$ and targeted organisms (i.e., prokaryotes, pico- or nanoeukaryotes, phototrophs or heterotrophs). The duration of incubations commonly varied from several hours [16], to days [17], or even weeks $[18,19]$. In the bay of Banyuls, two parameters, temperature and daylight, account for half of eukaryotic phytoplankton variability in one of the most extended metabarcoding time series (7 years) reported to date [9]. In this study, we combine microcosms and time series approaches in the bay of Banyuls to investigate the resilience of protists seasonality to light and temperature parameters, set up to mimic realistic seasonal conditions of daylight (photoperiod, intensity) and temperature. Over five days, incubations were performed that matched the gap between two successive samples in our high frequency (159 samples between 2015-2017) time series. These experiments aim at addressing the following questions: (1) How do abrupt changes in light and temperature alter picoeukaryotic communities? (2) How quickly can we change the protist communities from the initial season towards protist communities representative of the mimicked season? (3) How does the starting community dynamics influence microcosm outcome? 


\section{Material and Methods}

\section{Microcosms experiments}

Five liters of seawater were sampled at SOLA buoy in the bay of Banyuls $\left(42^{\circ} 31^{\prime} \mathrm{N}\right.$, $03^{\circ} 11^{\prime} \mathrm{E}$, France). Three $\mu \mathrm{m}$ filtration was used to remove large grazers and nanoplanktonic predators such as ciliates and flagellates since they can induce strong bias in small volume microcosms. Four times $400 \mathrm{ml}$ pre-filtered seawater were incubated in $500 \mathrm{ml}$ aerated culture flasks (Sarstedt) in homemade incubators equipped with white wide spectrum LEDs mimicking realistic light conditions (photoperiod and light intensity, Fig. 1). For each date, microcosms were conducted in triplicates. In addition, the complete set of 84 incubations ( 7 dates $x 4$ conditions $\mathrm{x}$ triplicates) was done twice with and without nitrate and phosphate enrichments (NP). Five $\mu \mathrm{M}$ of $\mathrm{NaNO}_{3}$ (SIGMA Aldrich) and $0.2 \mu \mathrm{M}$ of $\mathrm{Na}_{2} \mathrm{HPO}_{4}$ (SIGMA Aldrich) were added in NP enriched microcosms, which corresponded to maximal annual concentrations measured in the Banyuls Bay [9]. The planktonic abundance in the 56 microcosms (x3) was followed daily using an ACCURI C6 flow cytometer (BD Biosciences) as previously described [9]. After five days of incubation, triplicates were pooled, filtered on $0.22 \mu \mathrm{m}$ Sterivex (MerckMillipore) and stored at $-80{ }^{\circ} \mathrm{C}$ prior to DNA extraction.

\section{DNA extraction, amplification and sequencing}

DNA extracted from SOLA high-frequency time series and microcosm experiments were amplified and sequenced. DNA extractions were performed following the same protocol as Hugoni et al [20] and Lambert et al [9]. The V4 region of the 18S rRNA gene was amplified using the TAReuk primers 5'-CCAGCASCYGCGGTAATTCC (forward) and 5'ACTTTCGTTCTTGATYRATGA (reverse) modified from Stoeck et al [21]. Then, paired-end Illumina sequencing Miseq (2x250 base pairs) was performed by the Genotoul platform 
(Toulouse, France). SOLA high-frequency time series metabarcoding datasets are available on NCBI under accession number PRJNA579489.

\section{Bioinformatics treatment of metabarcoding data}

SOLA high-frequency time series and microcosms metabarcoding datasets were implemented in $\mathrm{R} v$ 3.6.1. The parameters were set as: $\operatorname{trimLeft}=\mathrm{c}(20,21), \max \mathrm{N}=0$, $\operatorname{maxEE}=c(2,2)$, truncQ $=2$ and truncLen $=c(250,250)$ respectively $c(280,230)$ to analyze the time series and the microcosms data. To allow comparison between the two datasets (e.g., in terms of shared Amplicon Sequence Variants (ASVs)), SOLA and microcosms ASVs and count tables were pulled together and re-processed under Mothur pipeline v1.35.1 [23] after keeping a single copy of each ASV using the unique.seqs() function, ASVs were taxonomically re-classified using the Protist Ribosomal Reference Database v4.11.1 [PR ${ }^{2}, 24$, https://pr2-database.org/] in which several protists groups were recently curated such as Chlorophyta [25], Haptophyta [26] and dinoflagellates [27].

\section{Statistics and data visualization}

Statistics and graphics were performed using R software version 3.6.1. Calculation of

117 Simpson diversity index [28] and richness (Sup. Data 1), Bray-Curtis dissimilarity matrix used for Non-parametric Multi-Dimensional Scaling (NMDS, Sup. Data 2) and SIMPER [similarity

119 percentage analysis, 29] test were performed using the vegan v. 2.5.6. R packages. Common $\mathrm{R}$ 120 packages such as Treemap (e. g. used for Sup. Data 4) or Hmisc to plot standard deviation were 121 also used to produce figures. All $\mathrm{R}$ scripts were formatted using the $R m d \mathrm{R}$ packages and are available in supplementary data (Sup. Data 1to Sup. Data 5). 


\section{Results}

125

126

127

\section{Flow cytometry analysis of microcosms}

Microcosm incubation experiments were performed in parallel to the high-frequency time series at SOLA buoy in the bay of Banyuls $\left(42^{\circ} 31^{\prime} \mathrm{N}, 03^{\circ} 11^{\prime} \mathrm{E}\right.$, France) between January 2015 and March 2017 [30]. Microbial community from SOLA were sampled and filtered at seven dates (between spring 2015 and autumn 2016) corresponding to each of the four seasons (Supplementary table 1). Samples filtered on $3 \mu \mathrm{m}$ were exposed in triplicates to realistic light conditions (photoperiod and light intensity) and temperature of the four seasons at the Banyuls latitude (Fig.1). After five days, photosynthetic cell abundance ranged from 290 (December 2016) to 32000 cells.ml $^{-1}$ (March 2015) with an average value of 6300 cells.ml $^{-1}$ in microcosms lacking nutrients supplementation (Supplementary Fig. 1 A) and from 540 cells.ml $^{-}$ ${ }^{1}$ (June 2015) to 100700 cells.ml ${ }^{-1}$ (March 2015) with an average value of 11730 cells.mll $^{-1}$ in NP enriched microcosms (Supplementary Fig. 1 B). Overall, the triplicate showed the same pattern of growth even though deviations were occasionally observed (e.g., for sample 3-3 at day 5). Different patterns of picophytoplankton growth were observed between microcosms. While cell growth was observed in microcosms 1 and 7, an increase in cell number occurred only at day 5 for Microcosms 2 and 5 and a decrease of picophytoplankton cells in all triplicates was observed over the time course of microcosm 4.

\section{Major eukaryotic groups recovered by metabarcoding}

Microcosms and environmental samples metabarcodes represented around 2 million reads, which were distributed into 2395 ASVs (Supplementary Table 2). Only ASVs represented by more than ten identical reads were taken into account. ASVs size ranged from 11 to 271707 reads (ASV assigned to Syndiniales) with an average size of 62 reads. ASVs were assigned to the nine eukaryotic supergroups present in the $\mathrm{PR}^{2}$ database taxonomy [24], yet 373 ASVs were unassigned at this taxonomic level. Stramenopiles, Alveolata, Archaeplastida and Rhizaria 
supergroups were the four most represented in microcosm ASVs (Fig. 2 A) while Alveolata,

150 Stramenopiles, Archaeplastida and Hacrobia were the main supergroups recovered from the 151 SOLA environmental time series ASVs (Fig. 2 B). Reproducible seasonal patterns of ASV 152 abundance were observed for both photosynthetic and heterotrophic (e.g. Opisthokonta and Alveolata) eukaryotes (Supplementary Fig. 2 A). Photosynthetic eukaryotes were detected primarily between late autumn and early Spring each year (Supplementary Fig. 2 B). reads (373 ASVs) were assigned to the photosynthetic Ochrophyta division (Fig. 2). In this division, reads were also assigned to the environmental clades MAST (marine Stramenopiles, 153204 reads, 156 ASVs) and MOCH (marine Ochrophyta, 105492 reads, 28 ASVs, [31]). In SOLA, Diatoms (Bacillaryophyta) drove Ochrophyta temporal dynamics, especially in late autumn, winter and early spring (Supplementary Fig. 3).

Alveolata were represented by 436920 reads (assigned to 757 ASVs), in which most were assigned to dinoflagellates (422 358 reads, 628 ASVs). In SOLA, Alveolata reads were assigned to Dinophyceae, Syndiniales (especially the Dino-group I clade 1) and to a lower extent to grazers such as the Spirotricheae Ciliophora (Supplementary Fig. 2). For example, in sample 2$1,85 \%$ of Alveolata reads corresponded to Syndiniales, which have been described as parasites of protists $[32,33]$. including Chlorophyta taxa (119 200 reads, 104 ASVs). In SOLA, Chlorophyta was the second major photosynthetic group (Dinoflagellates excluded). Dinoflagellates are commonly excluded 170 from photosynthetic groups when using metabarcoding because only half of the species are 171 photosynthetic. Moreover, Alveolata have large repeated genomes with numerous copies of the 18S rRNA gene, that can bias reads relative counts [34-36]. Remarkably, even with a limited 

even higher in winters 2015-16. The succession of Chlorophyta classes is detailed below.

\section{Microcosms ecological patterns}

The number of ASVs (i.e., richness) ranged from 52 in sample 1-4NP (water sampled in

March 2015 and incubated in December artificial conditions with nitrate and phosphate enrichment) to 636 in sample 6-4 (seawater sampled in October 2016 and set in December artificial conditions, Supplementary Table 1). On average, 177 ASVs were recovered per sample. The Simpson diversity index ranged from 0.41 in sample 5-4NP to 0.99, with an average Simpson index of 0.87 . During microcosm experiments, the diversity stayed high (between 0.8 and 1) except for June 2016 (Fig. 3), while the richness decreased in microcosm experiments compared to natural samples (Fig. 3). In general, microcosms acted as a filter, which reduced the number of ASVs without unbalancing the proportion of these ASVs in samples except for 4 June sampled microcosms and sample 6-4, which showed a higher richness but the same diversity than its relative natural counterpart samples (6-0 and 6-5). The natural samples 4-5 and 7-5 differed from other natural samples by their low Simpson's diversity index (around 6.5) and low richness (<100 ASVs, Fig. 3). The four June microcosm (2-1, 5-1, 5-1NP and 5-4NP) showed the lowest Simpson's diversity index in the dataset and a low richness $(<$ 100 ASVs, Fig. 3).

The representation of all natural and microcosms samples on an NMDS plot revealed that both natural communities and microcosm incubated samples were grouped according to sampling time rather than incubation conditions (Fig. 4). Natural samples clustered together with microcosms in June and October, March 2016 and December 2016 but were clearly separated in March 2015 ( 1-0 and 1-5) and December 2015 (3-0 and 3-5) indicating that 
samples (4-0 and 4-5) as well as (7-0 and 7-5) were well separated revealing that changes in communities had occurred in the field during microcosms. Microcosms incubated with or without nitrate and phosphate (NP) enrichment clustered together, suggesting that the enrichment did not induce major changes in microbial communities. (Procrustean statistic confirmed that microcosms with and without NP enrichment were highly correlated $\left(\mathrm{R}^{2}=0.86\right.$, Pvalue $=9.9 \mathrm{e}^{-5}$ ). For this reason, only microcosms lacking NP enrichment were kept in the analysis thereafter.

Most microcosm samples showed an increase in the relative abundance of Alveolata (e.g.,

207 Syndiniales dino group I clade and in a lesser extent Gyrodinium sp.), Opisthokonta (microcosms 1-1 to 1-4, 2-1 to 2-4, 5-2, 5- 3) or Rhizaria (for example in 2-2, 2-3, 5-2, 5-3, 6-2 and 6-3 samples) relative contributions (Fig. 4, Supplementary Fig. 2). These three groups were the most represented heterotrophic protists. Concerning photosynthetic groups, several microcosms (such as 4-2, 4-3, 5-2, 5-3, 7-1 and 7-3 samples, Fig. 5) differed from the others by their major contribution of Stramenopiles, which were usually associated to warmer incubations conditions (June and September). The Chlorophyta relative contributions were higher in microcosms sampled in March and June (sample 1-2 to 1-4, 2-4, 5-4, 4-1 and 4-4 for example, Fig. 5).

\section{Chlorophyta}

We next focused on Chlorophyta, which provides an interesting case study of seasonal succession with ASVs belonging to this group found all year round in SOLA. In the time series,

219161 ASVs were assigned to Chlorophyta, among which Mamiellophyceae (41 ASVs) and 220 Chlorodendrophyceae (9 ASVs) dominated the green microalgae community, both showing 221 clear seasonal patterns (Fig. 6 A). Mamiellophyceae represented $100 \%$ of Chlorophyta reads between January and March 2015 and in 2016, and more than $80 \%$ between October and 
to early September in 2015 and 2016. The number of reads assigned to other Chlorophyta classes and their relative contribution to Chlorophyta was too low to identify clear seasonal patterns. Mamiellophyceae and Chlorodendrophyceae did rarely co-occur in time (Fig. 6 A). Mamiellophyceae reads were recovered mainly in winter and early spring while Chlorodendrophyceae reads followed Mamiellophyceae peaks of abundance from late spring to late summer.

In microcosm experiments, the relative contribution of Chlorophyta usually decreased to the benefit of Alveolata or Stramenopiles reads, except in microcosm 1 (March 2015, Fig. 5). SIMPER analyses found between 2 and 4 ASVs assigned to Chlorophyta (e.g., M0005 Bathycoccus, M0010 Micromonas or M0050 Chlorodendrales) involved in the dissimilarity between samples in all incubations except for microcosm 6 (Supplementary Fig. 2). In the microcosm metabarcoding dataset, Chlorophyta reads were mainly assigned to Mamiellophyceae or Chlorodendrophyceae classes, but also to Chloropicophyceae (samples 3-2 to 3-4, 4-1 and 4-4) and Trebouxiophyceae (samples 1-1 to 1-4, 4-1 and 4-4, Fig. 6 B). Mamiellophycae dominated both incubated and natural samples in microcosms 3, 4 and 7, while

239 Chlorodendrophyceae dominated both incubated and natural samples in microcosms 2 and 5. In microcosm experiments 1 and 4, the dominant Chlorophyta class switched between natural and incubation samples indicating that incubations profoundly modified the Chlorophyta community. Experiment 1 and 4 (March) showed respectively Chlorodendrophyceae (ASV M0050, Supplementary Table 3) and Chloropicophyceae (ASV M0037, Supplementary Table

244 3) as dominant Chlorophyta class, while Mamiellophyceae dominated natural samples sampled 245 (1-0, 1-5 and 4-0, since very low reads of Chlorophyta were assigned to 4-5, Fig. 6). 
Bathycoccus peaks in late winter or early spring (Supplementary Fig. 4 A). In microcosms, the number of reads assigned to Mamiellophyceae was low in samples from the microcosms 1, 3 and 4. Nevertheless, Simper statistic tests unveiled that Micromonas (ASVs M0010 and M0046) and Bathycoccus (M0005) contributed significantly to the dissimilarities between samples in experiments 1, 3, 4 and 7 (Supplementary Table 3). Micromonas reads were recovered in samples 7-1, 7-3 and 7-4, while Bathycoccus dominated sample 4-4 (Supplementary Fig. 4 B). Mamiellophyceae (especially Micromonas) were usually more abundant under low temperature, i.e. when the applied temperature in microcosms was similar or lower than the environmental temperature (i.e., in conditions 1-March and 4-December the temperature was circa $14^{\circ} \mathrm{C}$ ).

\section{Discussion}

\section{Metabarcoding versus flow cytometry}

Metabarcoding of the $18 \mathrm{~S}$ rRNA gene V4 region revealed changes in microbial community composiion in response to seasonal conditions of light and temperature in all microcosms. Metabarcoding of $18 \mathrm{~S}$ rRNA is a non-selective but also non-quantitative method since it depends on the number of $18 \mathrm{~S}$ rRNA gene copies in protists genomes. Alveolata and to a lesser extent in Stramenopiles supergroups, which have large genomes with numerous copies of $18 \mathrm{~S}$ rRNA genes, are usually overestimated in metabarcodes datasets [35, 36]. In contrast,

267 Chlorophyta have relatively small genomes and few copies of the $18 \mathrm{~S}$ rRNA gene (e.g., 3 in Ostreococcus tauri) that lead to underestimating their number. Metabarcoding, therefore provides a good picture of the relative contribution of protists in global marine microbial communities [37] as well as of the diversity within specific groups such as diatoms [38] or

271 green microalgae [11] but does not provide information on the impact of cell growth or 
cytometry is a quantitative method that captures the daily change of cell numbers in microcosms over five days.

Changes in photosynthetic cell numbers, as determined by flow cytometry, were consistent between triplicates in most microcosms, although more variability was occasionally observed as seen in samples 7-2 and 3-3 ( Supplementary Fig. 1). Several factors could account for this variability. Though a filtration protocol was used to remove nano-phytoplankton containing predators, some larger-sized grazers of picophytoplankton can sometimes pass through the $3 \mu \mathrm{m}$ filter and induce disturbances in microcosms.

Flow cytometry data showed season dependent growth patterns that could be potentially explained by the initial density of photosynthetic cells in microbial communities. In winter, low photosynthetic cells density allows an exponential growth pattern in each experiment, while in June and March, photosynthetic communities should face both higher competition between microalgae and interactions such as parasitism or grazing, which generally occurs at higher photosynthetic cells density $[7,14]$.

\section{Effects of five days incubation on microbial communities}

The five-day incubations affected the different taxa differently, as illustrated for Hacrobia a division which comprises Cryptophyta and Haptophyta. For example, the contribution of Cryptophyta drastically decreased in all samples of microcosms 1 and 3 (March 2015 and December 2015), respectively, while natural samples showed a relatively high contribution of Cryptophyta reads (Fig. 5). In microcosm 6 (October 2016), however, the relative contribution of Haptophyta remains stable between natural communities and microcosms. These observations suggest that, unlike Haptophyta, Cryptophyta from the Banyuls Bay may be too difficult to grow or maintain in microcosms.

Stramenopiles was the division that showed the highest differences between microcosms and environmental samples (T5). Its relative contribution showed massive increase 
in several microcosms (such as 4-2, 4-3, 5-2, 5-3, 3-1, 3-2, 3-3, 7-1, 7-3, 7-4 and experiment 6 samples, Fig. 5). This increase in relative contribution should be interpreted in the light of flow cytometry data on day 5. In microcosms 4 (March 2016), we observed a dramatic decrease in photosynthetic cell number (from 10000 events to 2000), suggesting that the relative increase of Stramenopiles may result from cell mortality in other divisions, such as Archeaplastida. In microcosm 7 (December 2016) in contrast, the global increase in photosynthetic cells observed by flow cytometry suggested that this increase could correspond to diatoms bloom (Ochrophyta, Simper test,Supplementary Table 3). Diatoms occurred in several size fractions $[39,40]$ and recovering blooms of diatoms in picoeukaryotes microcosms were expected as they are an important phytoplanktonic organism in Mediterranean Sea waters and were already described to follow clear seasonal patterns $[41,42]$.

When Stramenopiles were less abundant, the natural communities and microcosms were often dominated by Alveolata, particularly Syndiniales [which contain known paratisoids, 32, 33] were clearly more abundant in microcosms than in environmental samples. In general, the higher relative contribution of heterotrophic protists and putative parasites, such as Syndiniales and Labyrinthule in microcosms suggest that the incubation process may enhance infection processes. In addition, the presence of bacterial grazers such as Choenoflagellates, or the ciliate, as Minoresa minuta yet [43] evoked that post-bloom conditions were met after five days of incubation days with a decrease of the photosynthetic contribution to the benefit of heterotrophs in several microcosms. The effect of "bottle enclosure" in small volume may be responsible for speeding up biological processes and unbalancing the autotrophic to heterotrophic ratio in microcosms $[16,44]$.

\section{Effects of light and temperature on microbial community composition in microcosms}

It is usually challenging to discriminate between light and temperature effects on 
September have similar day length and light conditions among the four seasonal conditions but

324 have an $8^{\circ} \mathrm{C}$ temperature difference. Comparing microcosms conditions of March and 325 September allows thus, to assess the respective effects of light and temperature. Incubations under these two months' conditions led to dramatic changes in community compositions, highlighting the importance of temperature in shaping microbial communities. In particular, Stramenopiles' relative contribution increased markedly in September warm condition but not in March cold condition as seen in microcosms. Stramenopiles contribution was also high under the June warm condition, confirming the temperature effect on Stramenopiles. Recent microcosm studies have emphasized the putative role of diatoms in a warming ocean, consistent with Stramenopiles exceeding natural relative contribution in the warmest incubated conditions [18]. However, it should be noted that in microcosms 3 and 6, the Stramenopiles contribution was high in a majority of conditions.

\section{Influence of initial communities}

Overall, the five-day incubation did not change the protist community enough to switch

337 the incubated community to a community representative of the applied seasonal condition in most microcosms (Fig. 4).. The inter-annual variations between 2015 and 2016 could explain most of the differences seen between microcosms sampled during similar seasons. In general, microcosms and natural samples 2015 and 2016 clustered together (Fig. 4), except for natural samples from microcosms 1 and 3 (March and December 2015). This suggested that winter

3422015 was different from winter 2016. The environmental parameters, especially temperature 343 and Chl, measured at the SOLA SOMLIT Station were similar between March 2015 and 2016

344 (around $12^{\circ} \mathrm{C}$ and $0.8-1.7 \mu \mathrm{g} / \mathrm{L}$ ). Inter-annual variability was driven mainly by dinoflagellates 345 blooms, which could account for the observed inter-annual differences in March and December between 2015 and 2016 (Supplementary Table 3). Differences between natural samples and 
incubation condition was sufficient to move the march 2015 natural community towards a "2016 like" community. The increase of temperature in 2015 induced a dinoflagellates bloom (e.g. Gyrodinium sp.) even though dinoflagellates were not blooming in natural samples. The blooming dynamics allow photosynthetic protists to rapidly dominate communities when environmental conditions became favorable. Blooms occurring in microcosms suggest that microalgae had encountered both favorable environmental conditions and out-competed other protists.

The dynamics of natural communities also seem to affect the outcome of microcosms. In microcosms 4 and 5 sampled before a bloom (Supplementary Fig. 2 B, Supplementary Fig. 3) Chrysiophyceae gold microalgae bloomed only in incubation conditions of warm temperature 2016) and 7 (December 2016) sampled at the beginning or during a diatom bloom, Stramenopiles bloomed under all applied seasonal conditions even at a lower temperature (Fig. 5, Supplementary Fig. 1). These results lead to the idea of a "community inertia" for blooming species such as diatoms: When the blooming dynamics was already triggered, this dynamics continued independently of the environmental parameters applied. In contrast, under pre-bloom conditions, the environmental parameters strongly influenced the communities in microcosms.

\section{Temporal succession of Chlorophyta}

Chlorophyta, in particular Mamiellophyceae, provide an interesting case study since their contribution is major in coastal waters [25, 45]. Micromonas and Bathycoccus peak in winter in the northern Mediterranean Sea where they can represent more than $50 \%$ of picoeukaryotes reads in winter with strong seasonal rhythms [6,9]. The presence of seasonal Chlorodendrophyceae was only recently confirmed using the V4 region of the 18S rRNA gene metabarcoding technique $[10,11]$. Chlorodendrophyceae is an abundant yet poorly documented 
samples and microcosms could be assigned only at the order level (Chlorodendrales) and to uncultured organisms (i.e., environmental sequences). SOLA Chlorodendrophyceae seasonal pattern (Fig. 5) was similar to this of Tetraselmis wettsteinii [46], a Chlorodendrophyceae species which was shown to form massive green blooms in the Bay of Naples in late spring and summer [47]. Since no reference sequence is available for $T$. wettsteinii, it is not possible to decipher if the abundant Chlorodendrophyceae ASV from the Banyuls Bay corresponds to this species.

Interestingly, Mamiellophyceae did not always dominate winter microcosm experiments (March and December, microcosms 1, 3, 4 and 7, Fig. 6). As discussed above, the community dynamics in the field may have prevented the growth of Mamiellophyceae even under favorable conditions in microcosms. Microcosms on pre-bloom communities (September) led to an increased contribution of Micromonas under the winter/ autumn incubation conditions (March, December) even though Micromonas ASV contributions were low in September natural communities. Although documented temperature preferences of Micromonas Mediterranean strains range between 25 and $30^{\circ} \mathrm{C}$ [48], we observe that Micromonas blooms around $14^{\circ} \mathrm{C}$ in natural communities and that winter/autumn temperatures and light conditions were more favorable to Micromonas in microcosms. The differences in temperature preferenda of Micromonas between culture strains and natural communities suggest factors other than temperature such as biotic interactions. Strong light especially may be inhibiting the growth of Mamiellophyceae in microcosms since we never observed Mamiellophyceae in June incubation conditions (similar temperature as in September incubation). Biotic interactions may also influence Micromonas' ecological niche, such as parasitism and competition.

Experiments 1, 4 and 5 were particularly interesting to investigate the temporal patterns of Chlorophyta that occurred in SOLA natural communities (Fig. 6). Mamiellophyceae, which dominated Chlorophyta in natural communities of March 2015, were still detected together with 

replaced them in the other microcosms of March 2015. In March 2016, a switch between

400 Mamiellophyceae and Chloropicophyceae occurred under low temperature incubations. These

401 results suggest that (i) the succession of Mamiellophyceae to Chlorodendrophyceae in 402 microcosms reflect their succession in the field and (ii) the switch from Mamiellophyceae to 403 Chlorodendrophyceae occurs independently of temperature and light conditions and is mostly influenced by ecological processes such as biotic interactions. Reads assigned to several grazers such as ciliates or parasites such as Syndiniales were found at that time, but unfortunately no ecological relationships are known between Mamiellophyceae and specific heterotrophic protists. Furthermore viruses (which were not followed in this study) may significantly affect microalgal populations and ecological interactions [7, 49].

\section{Conclusion}

410 Our combined approach of microbial diversity monitoring at SOLA together with microcosms

411 simulating seasonal conditions of light and temperature unveiled several aspects of the regulation of phytoplankton seasonality by light and temperature: (1) overall a five days incubation was not sufficient to completely reshape the initial microbial communities, (2) the in situ dynamics of phytoplankton starting communities modulated the impact of applied seasonal conditions in microcosms as seen for Diatoms or Chlorodendrophyceae in bloom or post-bloom conditions. (3) In pre-bloom conditions, phytoplanktonic species were the most sensitive to light and temperature conditions. Diatoms were favored by higher temperature independently of light, while Mamiellophyceae increased under lower temperatures and lower light intensities (December and March). Altogether, our results suggest that light and temperature seasonal conditions play an importantrole in regulating phytoplankton in pre-bloom conditions and biotic interactions may be preponderant in bloom and post-bloom conditions. 
bioRxiv preprint doi: https://doi.org/10.1101/2021.03.03.433693; this version posted March 4, 2021. The copyright holder for this preprint (which was not certified by peer review) is the author/funder. All rights reserved. No reuse allowed without permission.

Tragin et al. - Seasonal Microcosms - p. 19

\section{Acknowledgments}

424 We would like to thank the captain and the crew of the RV 'Nereis II' for collecting the 425 samples and the Service d'Observation", particularly Eric Maria and Paul Labatut, for 426 processing of the samples. We are also grateful to Urania Christaki for constructive exchanges

427 during manuscript writing, Pierre Galand for providing advice in statistical analyses and Adam 428 Monier for constructive reading of the manuscript. This work was supported by the French 429 Agence Nationale de la Recherche through the Photo-Phyto project (ANR-14-CE02-0018) to 430 FYB. 


\section{REFERENCES}

432 1. Giesbrecht W. Systematik und Faunistik der pelagischen Copepoden des Golfes von Neapel und der angrenzenden Meeres-abschnitte. 1892. R. Friedlander \& Sohn, Berlin,. 1981; 2: 317-333.

436 3. Péragallo H, Péragallo H, Péragallo M. Diatomées marines de France et des districts maritimes voisins,. 1897. M. J. Tempère, Grez-sur-Loing,.

438 4. Travers A, Travers M. Les Silicoflagellés du Golfe de Marseille. Mar Biol 1968; 1: 285-288.

439 5. Daday EJ. Systematische Übersicht der Dinoflagellaten des Golfs von Naples. Terménez Füzetek 1888; 11: 98-109.

8. Gomez F, Gorsky G. Annual microplankton cycles in Villefranche Bay, Ligurian Sea, NW Mediterranean. $J$ Plankton Res 2003; 25: 323-339.

9. Lambert S, Tragin M, Lozano JC, Ghiglione JF, Vaulot D, Bouget FY, et al. Rhythmicity of coastal marine picoeukaryotes, bacteria and archaea despite irregular environmental perturbations. ISME J 2019; 13: 388401.

10. Piredda R, Tomasino MP, D’Erchia AM, Manzari C, Pesole G, Montresor M, et al. Diversity and temporal patterns of planktonic protist assemblages at a Mediterranean Long Term Ecological Research site. FEMS

12. Cadier M, Gorgues T, Sourisseau M, Edwards CA, Aumont O, Marié L, et al. Assessing spatial and Microbiol Ecol 2017; 93: fiw200. 

Parasitic Killers. Science (80- ) 2008; 322: 1254-1257.

15. Conan P, Testor P, Estournel C, D’Ortenzio F, Durrieu de Madron X. Observing Winter Mixing and Spring Bloom in the Mediterranean. Eos (Washington DC) 2018; 99.

466 16. Calvo-Díaz A, D́az-Pérez L, Suárez LÁ, Morán XAG, Teira E, Marañón E. Decrease in the autotrophic-toheterotrophic biomass ratio of picoplankton in oligotrophic marine waters due to bottle enclosure. Appl Environ Microbiol 2011; 77: 5739-5746.

17. Tortell P, DiTullio G, Sigman D, Morel F. CO2 effects on taxonomic composition and nutrient utilization in an Equatorial Pacific phytoplankton assemblage. Mar Ecol Prog Ser 2002; 236: 37-43.

18. Kling JD, Lee MD, Fu F, Phan MD, Wang X, Qu P, et al. Transient exposure to novel high temperatures reshapes coastal phytoplankton communities. ISME J 2020; 14: 413-424.

19. Nielsen LT, Jakobsen HH, Hansen PJ. High resilience of two coastal plankton communities to twenty-first century seawater acidification: Evidence from microcosm studies. Mar Biol Res 2010; 6: 542-555.

21. Stoeck T, Bass D, Nebel M, Christen R, Jones MDM, Breinner H-W, et al. Multiple marker parallel tag environmental DNA sequencing reveals a highly complex eukaryotic community in marine anoxic water. Mol Ecol 2010; 19: 21-31.

22. Callahan BJ, McMurdie PJ, Rosen MJ, Han AW, Johnson AJA, Holmes SP. DADA2: High-resolution

23. Schloss PD, Westcott SL, Ryabin T, Hall JR, Hartmann M, Hollister EB, et al. Introducing mothur: opensource, platform-independent, community-supported software for describing and comparing microbial

24. Guillou L, Bachar D, Audic S, Bass D, Berney C, Bittner L, et al. The Protist Ribosomal Reference database microalgae in marine systems: an overview based on 18S rRNA gene sequences. Perspect Phycol 2016; 3: $141-154$.

26. Edvardsen B, Egge ES, Vaulot D. Diversity and distribution of haptophytes revealed by environmental 
27. Mordret S, Piredda R, Vaulot D, Montresor M, Kooistra WHCF, Sarno D. dinoref : A curated dinoflagellate (Dinophyceae) reference database for the 18S rRNA gene. Mol Ecol Resour 2018; 18: 974-987.

28. Simpson EH. Measurement of diversity. Nature 1949; 163: 688-688.

29. Clarke KR. Non $\square$ parametric multivariate analyses of changes in community structure. Aust J Ecol 1993; 18: $117-143$.

30. Pereira O, Hochart C, Boeuf D, Auguet JC, Debroas D, Galand PE. Seasonality of archaeal proteorhodopsin and associated Marine Group IIb ecotypes (Ca. Poseidoniales) in the North Western Mediterranean Sea. ISME J 2020.

31. Massana R, del Campo J, Sieracki ME, Audic S, Logares R. Exploring the uncultured microeukaryote majority in the oceans: reevaluation of ribogroups within stramenopiles. ISME J 2014; 8: 854-66.

33. Peterfi LS, Manton I. Observations with the electron microscope on Asteromonas gracilis Artari emend. ( Stephanoptera gracilis (Artari) wisl.), with some comparative observations on Dunaliella Sp. Br Phycol Bull 1968; 3: 423-440.

34. Gómez F. A quantitative review of the lifestyle, habitat and trophic diversity of dinoflagellates (Dinoflagellata, Alveolata). Syst Biodivers 2012; 10: 267-275. ecosystems with quantitative PCR of the 18S rRNA gene. FEMS Microbiol Ecol 2005; 52: 79-92. generation sequencing approach. Front Mar Sci 2019; 6. coastal waters and sediments as revealed by high-throughput sequencing. Environ Microbiol 2015; 17:

519 38. Malviya S, Scalco E, Audic S, Vincent F, Veluchamy A, Poulain J, et al. Insights into global diatom distribution and diversity in the world's ocean. Proc Natl Acad Sci U S A 2016; 113: E1516-25. Plankton Res 2003; 25: 323-339. 
bioRxiv preprint doi: https://doi.org/10.1101/2021.03.03.433693; this version posted March 4, 2021. The copyright holder for this preprint (which was not certified by peer review) is the author/funder. All rights reserved. No reuse allowed without permission.

Tragin et al. - Seasonal Microcosms - p. 23

marine ecosystems. FEMS Microbiol Rev 2008; 32: 795-820.

525 41. Zingone A, D’Alelio D, Mazzocchi MG, Montresor M, Sarno D, Balestra C, et al. Time series and beyond: Multifaceted plankton research at a marine Mediterranean LTER site. Nat Conserv 2019; 34: 273-310.

527 42. Leblanc K, Quéguiner B, Diaz F, Cornet V, Michel-Rodriguez M, Durrieu De Madron X, et al. Nanoplanktonic diatoms are globally overlooked but play a role in spring blooms and carbon export. Nat Commun 2018; 9.

530 43. del Campo J, Not F, Forn I, Sieracki ME, Massana R. Taming the smallest predators of the oceans. 2013.

531 44. Gieskes WWC, Kraay GW, Baars MA. Current 14C methods for measuring primary production: Gross underestimates in oceanic waters. Netherlands J Sea Res . 1979. Elsevier. , 13: 58-78

45. Not F, Latasa M, Marie D, Cariou T, Vaulot D, Simon N. A single species, Micromonas pusilla (Prasinophyceae), dominates the eukaryotic picoplankton in the Western English Channel. Appl Environ Microbiol 2004; 70: 4064-72.

536 46. Schiller J. Vorläufige Ergebnisse der Phytoplanktonuntersuehungen auf den Fahrten S. M.S. 'Najade' in der Adria. II. Flagellaten und Chlorophyceen. Sitzungsberichte der Akad der Wissenschaften Wien, Math Klasse 1913; 122: 621-63.

47. Throndsen J, Zingone A. Tetraselmis wettsteinii (Schiller) throndsen comb. nov. and its occurrence in golfo di napoli. G Bot Ital 1988; 122: 227-235.

541 48. Demory D, Baudoux AC, Monier A, Simon N, Six C, Ge P, et al. Picoeukaryotes of the Micromonas genus: sentinels of a warming ocean. ISME J 2019; 13: 132-146.

543 49. Fuhrman JA. Marine viruses and their biogeochemical and ecological effects. Nature . 1999., 399: 541-548 


\section{Figure Legends}

546 Fig. 1: Description of the microcosm experimental procedure. Sea water was sampled 3 to 4 547 times a year in 2015 and 2016 at SOLA SOMLIT station off Banyuls-sur-mer (France). The 7 548 seawater samples were incubated in artificial conditions mimicking average seasons. Each 549 experiment was re-named by a code combining the sampling date (1 to 7$)$ and the incubation 550 conditions code. Incubation codes were 0 to 5: 0 was SOLA control sample, 1 to 4 refers to incubation conditions (spring - green - 1, summer - yellow - 2, autumn - red - 3 and winter blue - 4) and 5 refers to SOLA next control sample (4 to 10 days after initial sampling).

Fig. 2: Treemaps representing the distribution of V4 region of the $18 \mathrm{~S}$ rRNA gene metabarcodes in supergroups and major divisions of marine protists. Bold legends refer to lineages hosting photosynthetic protists. A- Global taxonomic diversity in the 56 microcosm samples, B- Global taxonomic diversity in 140 SOLA times series samples.

557 Fig. 3: Number of ASV per microcosm samples versus the Simpson diversity index. Only 558 ASVs represented by more than 10 reads and sample with more than 4000 sequenced reads were taken into account. Each dot and label correspond to a microcosm experiment number. Colors represent the month when the sea water was sampled and the dot shape represent either the nutriment conditions (incubation with Nitrate and Phosphate enrichment) or the natural samples from environmental time series (bold labels). Labels refer to the sampling-incubation condition codes as defined in Fig. 1 and Supplementary Table 1.

564 Fig. 4: Non-parametric Multi-Dimensional Scaling (NMDS) representing microcosm experiment and natural samples protist communities. The NMDS calculation was based on a Bray-Curtis distance matrix and resulted in an acceptable stress value (0.2039). Only ASVs

567 represented by more than 10 reads and sample with more than 4000 sequenced reads were taken into account. No environmental parameters are plotted on the NMDS graphic since none had a 
P-value (100 permutations) lower than 0.05. Labels refers to the sampling-incubation condition

570 codes as defined in Fig. 1 and Supplementary Fig. 1 and the dot shape represents either the

571 nutriment conditions (incubation with Nitrate and Phosphate enrichment) or the natural samples

572 from environmental time series (bold labels). A- Colors represents the month when the sea

573 water was sampled. B- Colors represent the incubation conditions (artificial month: temperature

574 and daylight length mimicking seasons).

575 Fig. 5: Barplot representing the percentage of reads assigned to each eukaryotic taxonomic 576 supergroup in microcosm incubated without Nitrate and Phosphate enrichment and natural 577 samples. Sequences assigned to Metazoans were deleted from the dataset. Colors in the barplot 578 refer to supergroups, colors in the legend correspond to the month, when the initial sea water 579 was sample and letters (in grey) to the incubation conditions (i.e. artificial month): March (M), 580 June (J), September (S) and December (D). A- Natural and incubated samples from March 2015 581 and 2016. B- Natural and incubated samples from June 2015 and 2016. C- Natural and 582 incubated samples from December 2015 and 2016. D- Natural and incubated samples from 583 September 2016.

584 Fig. 6: Chlorophyta classes contribution: A- Relative contribution of Chlorophyta classes (\%) in the SOLA environmental high sampling frequency time series. Grey dots and lines point out the sampling date of sea water incubated for microcosm experiments. B- Barplots represent the number of reads per Chlorophyta classes in the 4 microcosm experiments and their associated natural sample. Colors in the barplot refer to Chlorophyta classes, colors in the legend correspond to the month, when the initial sea water was sample and letters (in grey) to the incubation conditions (i.e. artificial month): March (M), June (J), September (S) and December (D). 


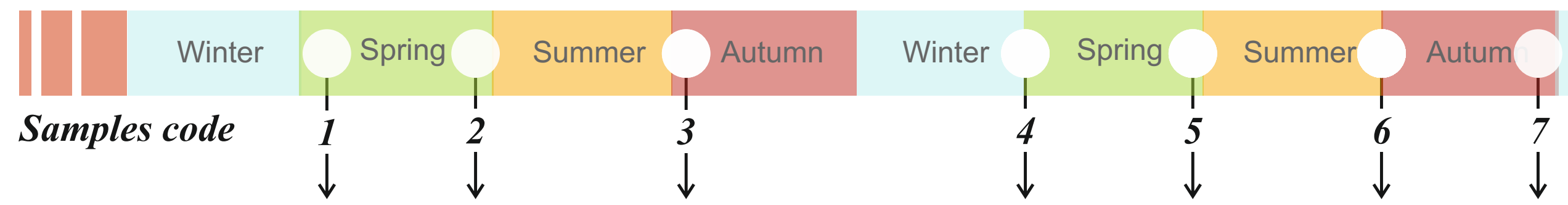

bioRxiv preprint doi: https://doi.org/10.1101/2021.03.03.433693; this version posted March 4, 2021. The copyright holder for this preprint

7 Natural seawater samples (Banyuls Bay) $400 \mathrm{ml}(\mathrm{x} 3)$, pre-filtration on $3 \mu \mathrm{m}$
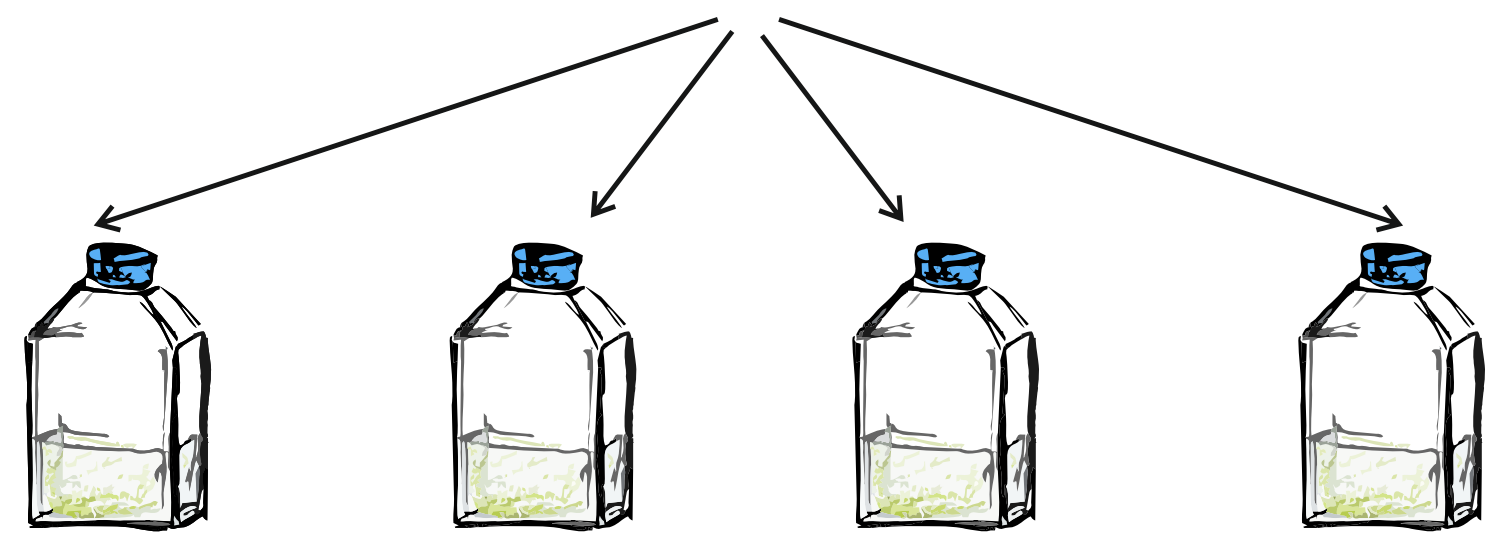

5 days incubation

$\begin{array}{lcccc}\text { Incubation code } & \mathbf{1} & \mathbf{2} & \mathbf{3} & \mathbf{4} \\ \text { Artificial season } & \text { March } & \text { June } & \text { September } & \text { December } \\ \text { Temperature }\left({ }^{\circ} \mathrm{C}\right) & 12.2 & 18.8 & 20.7 & 14.4 \\ \text { Day length }(\mathrm{h}) & 11.95 & 14.75 & 12.08 & 9.13\end{array}$

Nomenclature:

- 10 sampled March 30. 2015, no incubation, SOLA control.

- 11 sampled March 30. 2015 and incubated in March artificial conditions.

- 12 sampled March 30. 2015 and incubated in June artificial conditions.

- 15 sampled March 30. 2015, no incubation, «final » SOLA control sample.
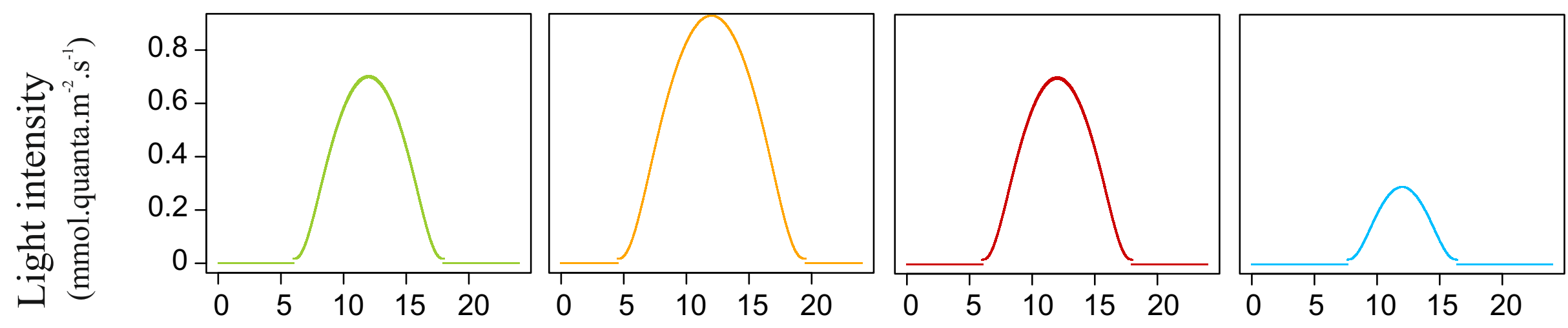

Day length (h)

Filtration, extraction, PCR and sequencing

- $0.22 \mu \mathrm{m}$ sterivex

- V4 region of the $\mathbf{1 8 S}$ rRNA gene (Piredda et al. 2017):

Forward [5'-CCAGCASCYGCGGTAATTCC]

Reverse [5'-ACTTTCGTTCTTGATYRATGA]

- Illumina Miseq (250 base pairs x2) 


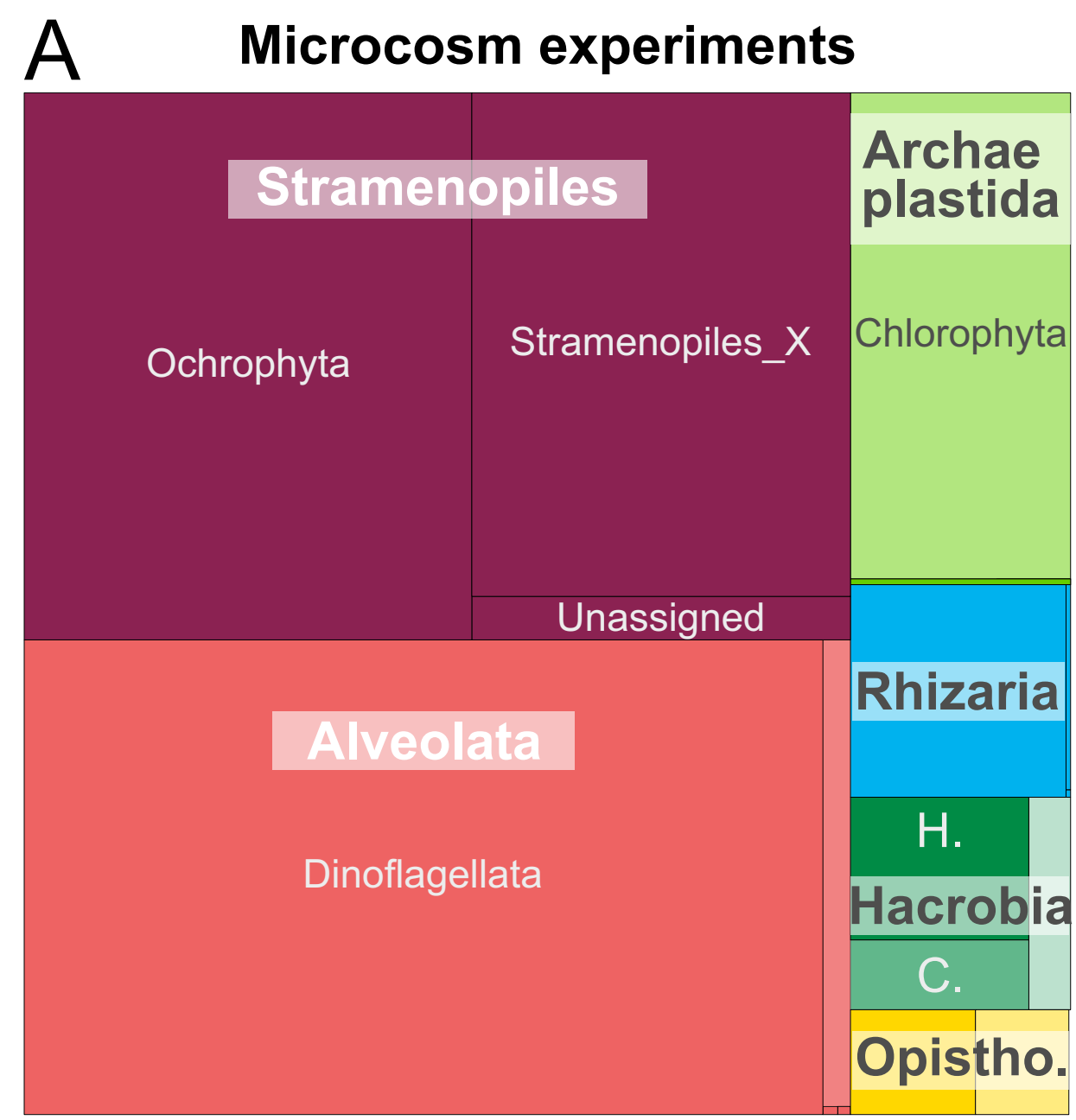

\section{B SOLA environmental time series}

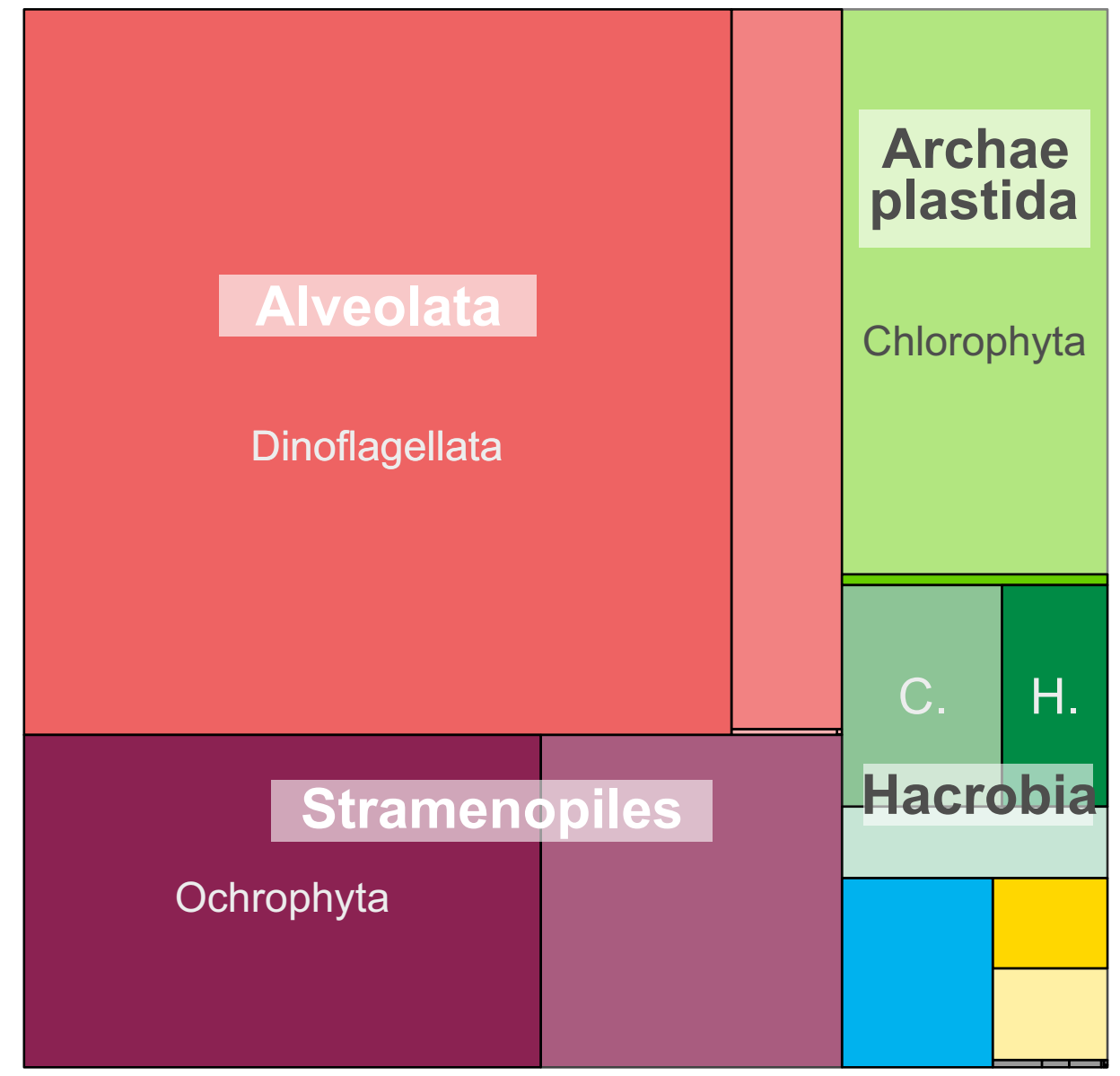

Alveolata/Dinoflagellata

Alveolata/Cilliophora

Stramenopiles/Ochrophyta

Stramenopiles/Stramenopiles_X

Unassigned Stramenopiles
Hacrobia/Haptophyta (H.)

Hacrobia/Cryptophyta (C.)

Hacrobia/Others

Archaeplastida/Chlorophyta

Archaeplastida/Others
Rhizaria

Opisthokonta/fungi Opisthokonta/Others

Others

\section{Figure 2}


Figure 4

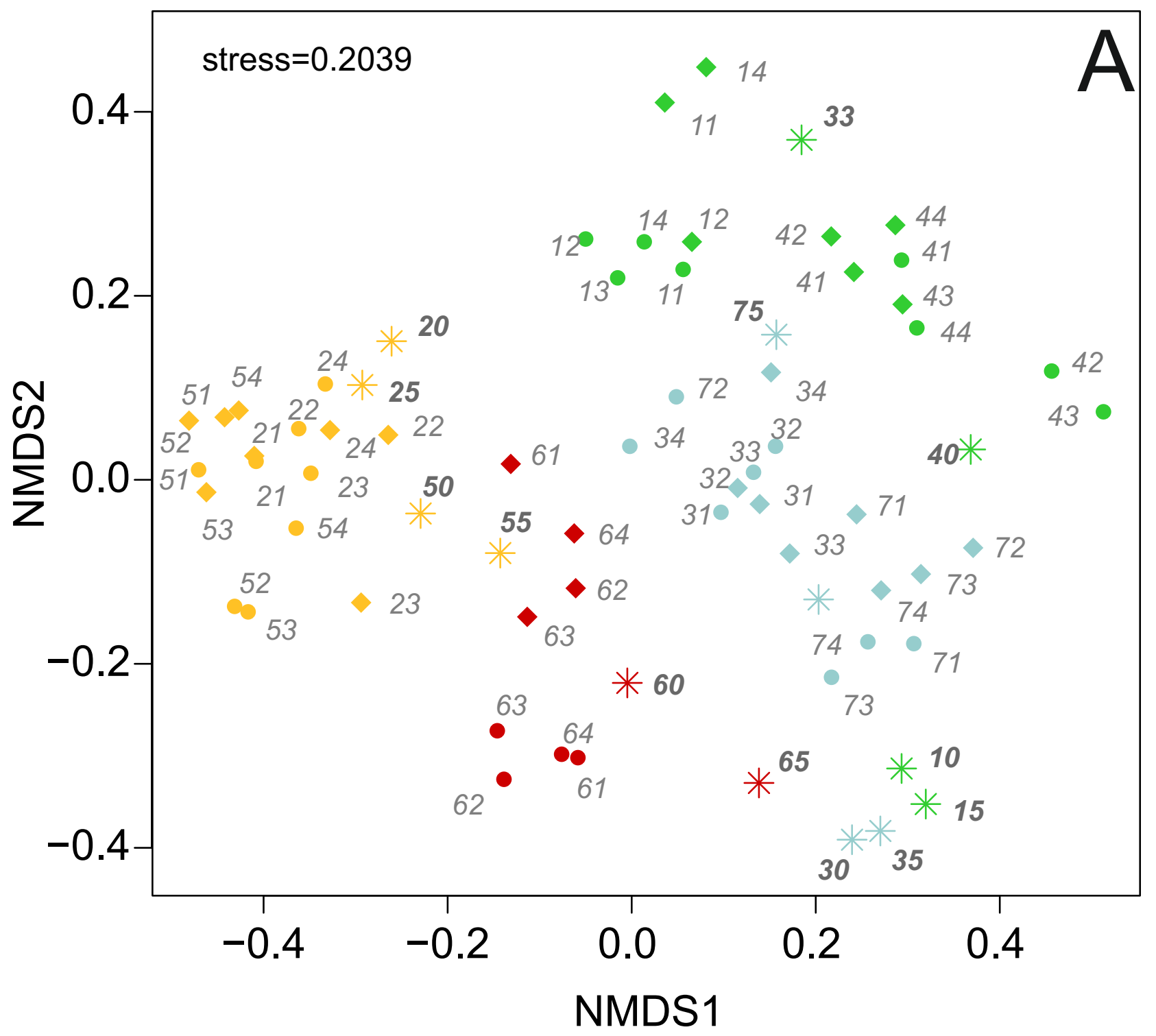

A
Sampling

- March

- June

- Oct.

- Dec.

Incubation

- March

- June

- Sept.

- Dec.

* T0 \& T5 control

- Natural

- NP enrichment

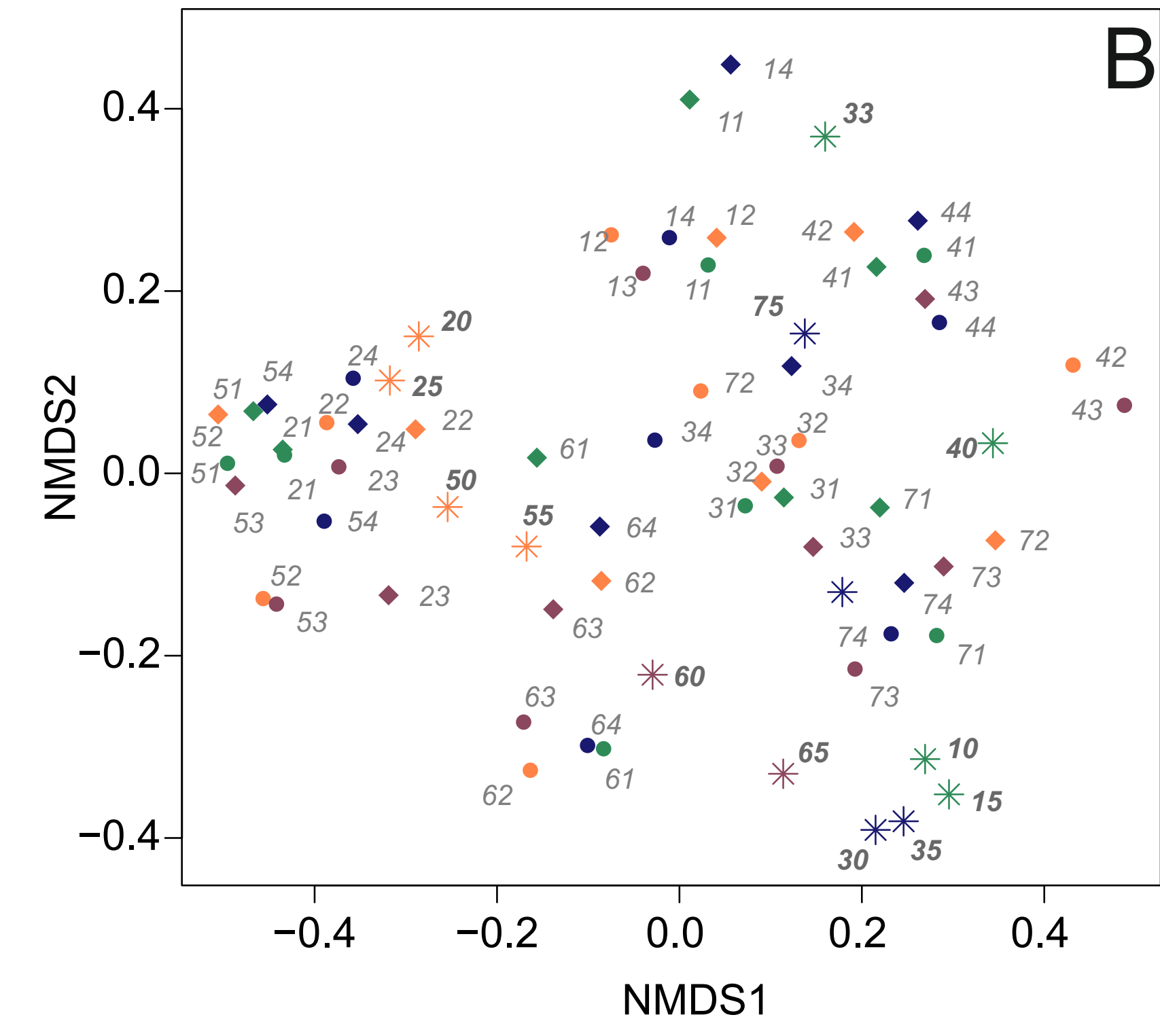


Figure 5

\section{Supergroup of eukaryotes}

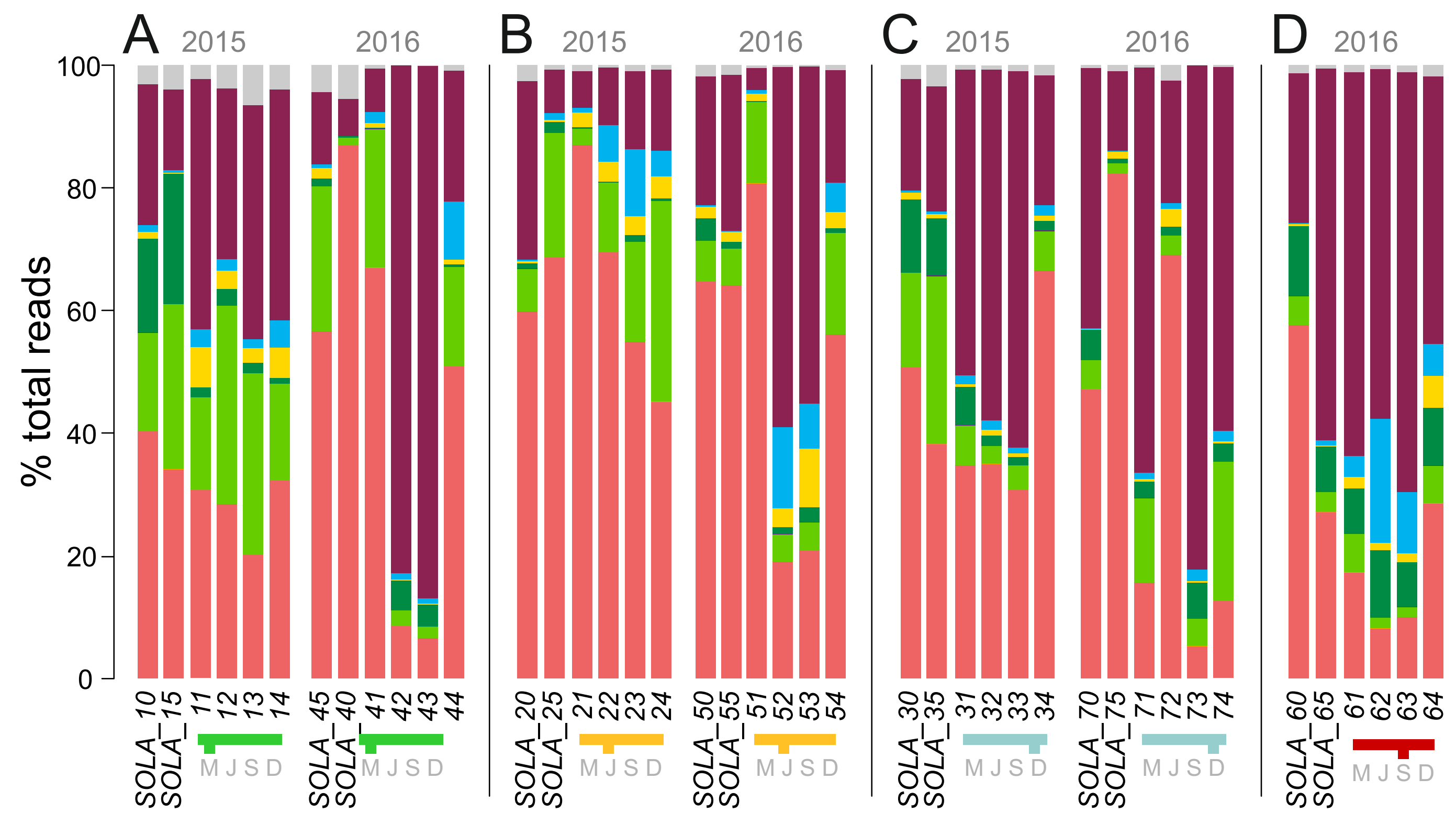

\begin{tabular}{|lll|}
\hline Alveolata & Archaeplastida & Opisthokonta \\
Amoebozoa & Excavata & Rhizaria \\
Apusozoa & Hacrobia & Stramenopiles \\
\hline
\end{tabular}




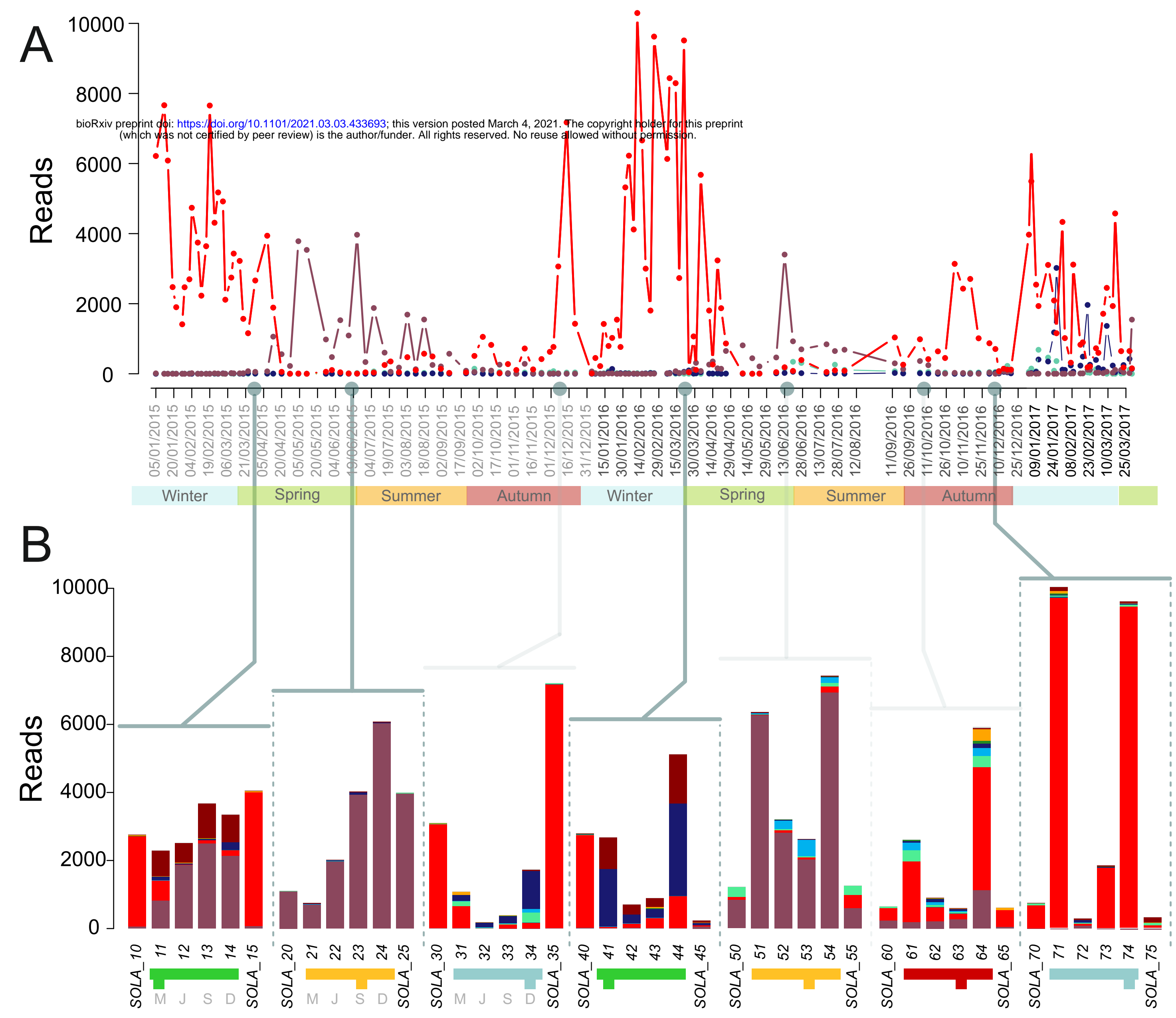

\begin{tabular}{|ll|}
\hline Chlorodendrophyceae & Trebouxiophyceae \\
Mamiellophyceae & Pseudoscourfieldiales \\
Prasinophytes clade IX & Nephroselmidophyceae \\
Chloropicophyceae & Prasinococcales \\
Pyramimonadales & Unclassified \\
\hline
\end{tabular}

Figure 6 


\section{Supplementary Information}

2 Supplementary Table 1: Microcosms experimental conditions. 'Sample' was the original

3 sample names, that were translated into a two digit code 'Code'. Sample names starting by

4 'SOLA_' are natural control samples extracted from the environmental time series. 'Sequencing

5 Date' refers to the date of sea water filtration after 5 days incubations to prepare DNA 6 extraction. 'Artificial month' refers to the light and temperatures incubation conditions:

7 Daylight duration ranged from 9.13 hours in December to 14.75 hours in June, with maximum

8 light intensity between 0.3 and 0.9 mmol.quanta. $\mathrm{m}^{-2} \cdot \mathrm{s}^{-1}$ corresponding to the 3 meter depth of 9 sampling at SOLA. Applied temperature corresponded to the average temperature of the sea at 10 SOLA recorded between 2007 and 2014: in March $\left(12.2{ }^{\circ} \mathrm{C}\right)$, June $\left(18.8^{\circ} \mathrm{C}\right)$, September $(20.7$

$\left.1{ }^{\circ} \mathrm{C}\right)$ and December $\left(14.4{ }^{\circ} \mathrm{C}\right)$. The nutrients enrichment are coded as a Boolean variable, T- 5 $\mu \mathrm{M}$ of $\mathrm{NaNO}_{3}$ and $0.2 \mu \mathrm{M}$ of $\mathrm{Na}_{2} \mathrm{HPO}_{4}$ (SIGMA Aldrich) were added to microcosms (NP

13 microcosms) versus F- no nutriments supplementation. All microcosms were sampled at the 14 surface.

15 Supplementary Table 2: ASVs table of microcosm experiments and control natural samples: $\mathrm{PR}^{2}$ taxonomy and number of reads per samples.

17 Supplementary Table 3: Set of eight tables summarizing pairwise simper statistical test: the 18 composition of each of the 6 samples belonging to the same microcosm experiment 19 (microcosms 1 to 7) was compared as well as the March natural samples (1-0, 1-5, 4-0, 4-5).

20 The taxonomical assignation of the ASVs, which influenced the most the dissimilarities 21 between microcosms, are listed next to each table and cumulative dissimilarity \% value represented by the 4 top ASVs is mentioned inside the tables. 
Supplementary Figure 1: Evolution of eukaryotic photosynthetic cell numbers (pico- and nano-phytoplankton communities) during microcosm experiments incubation followed by flow cytometry measurements. The colors of the dots refers to incubation condition and the label corresponds to sampling-incubation condition codes as defined in Fig. 1 and Supplementary Table 1Supplementary Information

Supplementary Table 1. A- Microcosms incubated without nutrients supplementation. BMicrocosms experiments enriched with nitrate and phosphate.

Supplementary Figure 2: Seasonal patterns of reads assigned to protists taxonomic groups in SOLA environmental high-frequency time series. Grey dots correspond to the sampling dates of sea water for microcosms experiments. A- Pattern of abundance of the V4 metabarcodes assigned to the nine eukaryotic supergroups. Metabarcodes assigned to Metazoan were not deleted from the Opisthokonta. Photosynthetic supergroups are in bold in the legend. B- Pattern of abundance of the numbers of the V4 metabarcodes assigned to the four major photosynthetic divisions (dinoflagellates excluded).

Supplementary Figure 3: Seasonal patterns of reads assigned to Ochrophyta microalgae (photosynthetic division of Stramenopiles) in SOLA environmental high-frequency time series. Grey dots correspond to the sampling dates of sea water for microcosms experiments. APattern of abundance of the V4 metabarcodes assigned to Ochrophyta classes. B- Pattern of abundance of V4 metabarcodes assigned to Bacillariophyta (Ochrophyta) families, C- Pattern of abundance of the numbers of the V4 metabarcodes assigned to the Bacillariophyta genera. The most abundant genera are in bold in the legend.

Supplementary Figure 4: Mamiellophyceae genera contribution in SOLA environmental time series and microcosms. A- Seasonal patterns of reads assigned to Mamiellophyceae genera at SOLA. Note that only the two most abundant genera Micromonas and Bathycoccus can be seen 
47 on the graph. Grey dots correspond to the sampling dates of sea water for microcosms

48 experiments. B- Barplot representing the number of reads per Mamiellophyceae genera in 4

49 microcosm experiments and their associated natural sample. Colors in the barplot refer to

50 Mamiellophyceae genera, colors in the legend correspond to the month, when the initial sea

51 water was sample and letters (in grey) to the incubation conditions (i.e. artificial month): March

52 (M), June (J), September (S) and December (D).

54 Supplementary Data 1: Script used to compute and plot ASVs richness versus Simpson's 55 diversity index (Fig. 2) as Rmarkdown.html file.

56 Supplementary Data 2: Script used to compute and plot (Fig. 3) as Rmarkdown.html file.

57 Supplementary Data 3: Script used to compute and draw barplots (Fig. 4, Fig. 5B and Fig. S 5B) as Rmarkdown.html file.

59 Supplementary Data 3: Script used to compute and plot Treemap (Supplementary figure 2) as Rmarkdown.html file.

61 Supplementary Data 5: Script used to plot Fig. 5A, Supplementary figures 3 to 6 as 62 Rmarkdown.html file. 


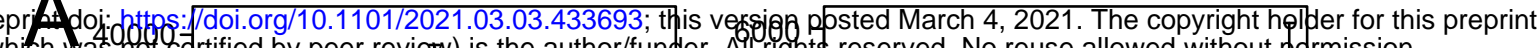
(whith was hoftefrtified by peer revietv) is the author/ffunder. All right\$ reserved. No reuse allowed withouł bermission.
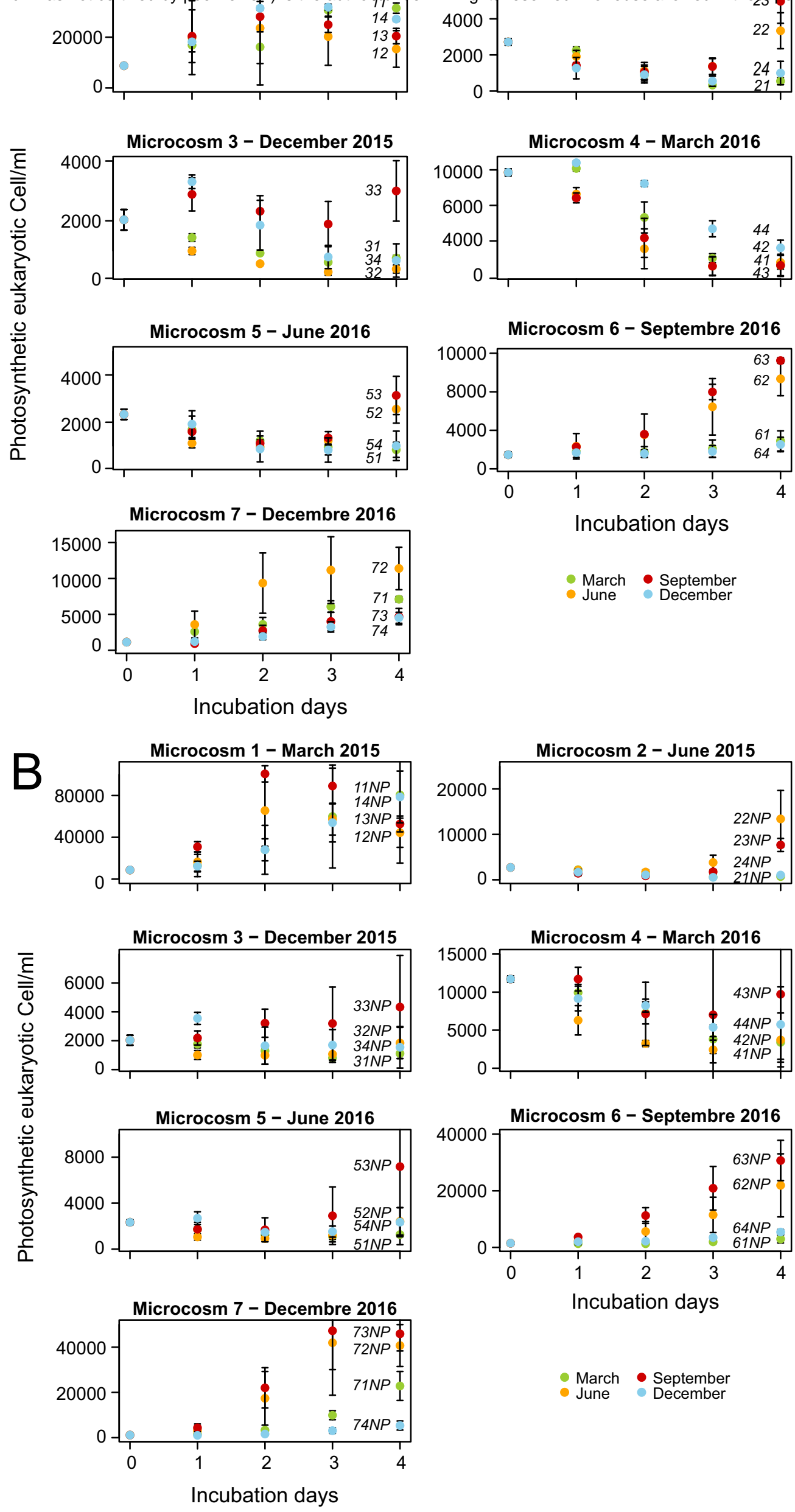

March September

June December

Supplementary Figure 1: Evolution of eukaryotic photosynthetic cell numbers (pico- and nano-phytoplankton communities) during microcosm experiments incubation followed by flow cytometry measurements. The colors of the dots refers to incubation condition and the label corresponds to sampling-incubation condition codes as defined in Fig. 1 and Supplementary Table 1. A- Microcosms incubated without nutrients supplementation. BMicrocosms experiments enriched with nitrate and phosphate. 


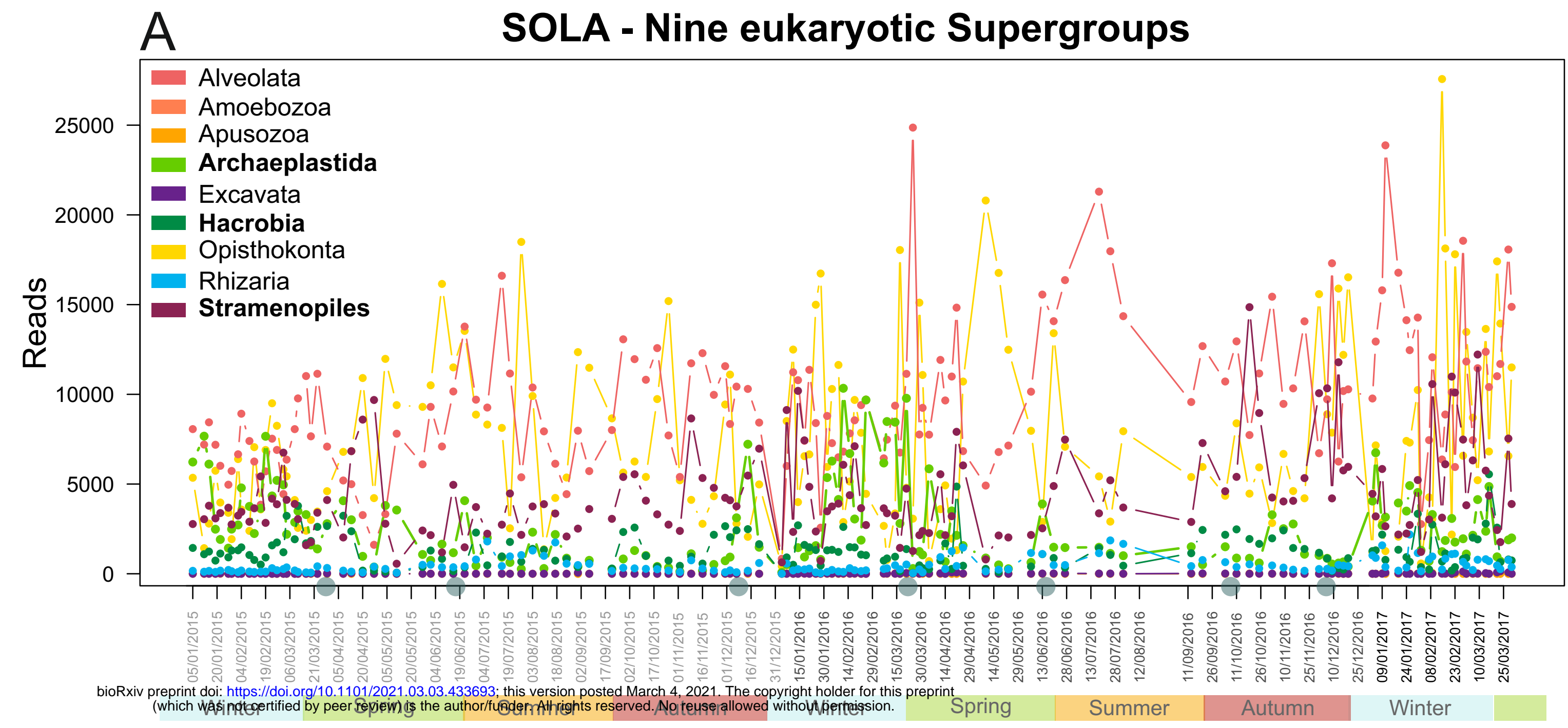

B SOLA - Four photosynthetic divisions

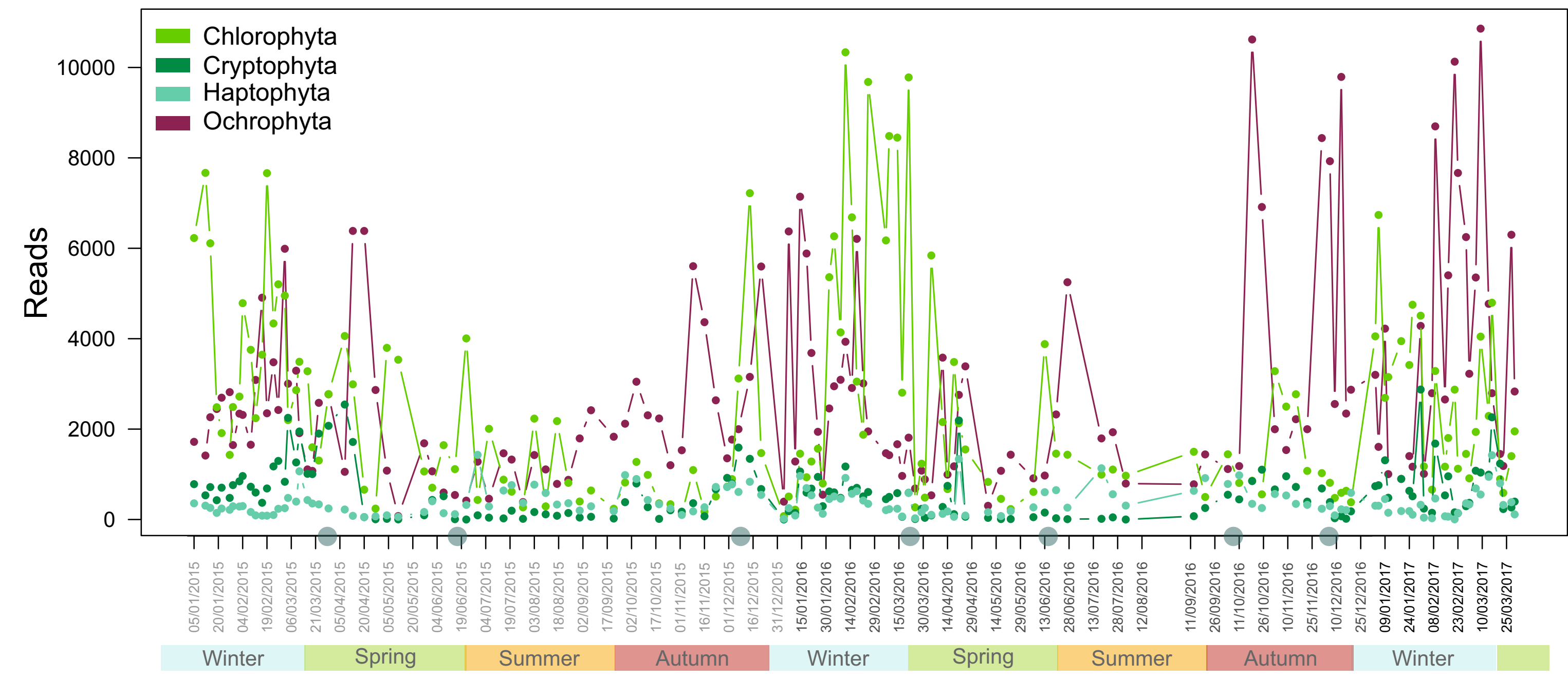

Supplementary Figure 2: Seasonal patterns of reads assigned to protists taxonomic groups in SOLA environmental high-frequency time series. Grey dots correspond to the sampling dates of sea water for microcosms experiments. A- Pattern of abundance of the V4 metabarcodes assigned to the nine eukaryotic Supergroups. Metabarcodes assigned to Metazoan were not deleted from the Opisthokonta. Photosynthetic supergroups are in bold in the legend. B- Pattern of abundance of the numbers of the V4 metabarcodes assigned to the four major photosynthetic Divisions (dinoflagellates excluded). 


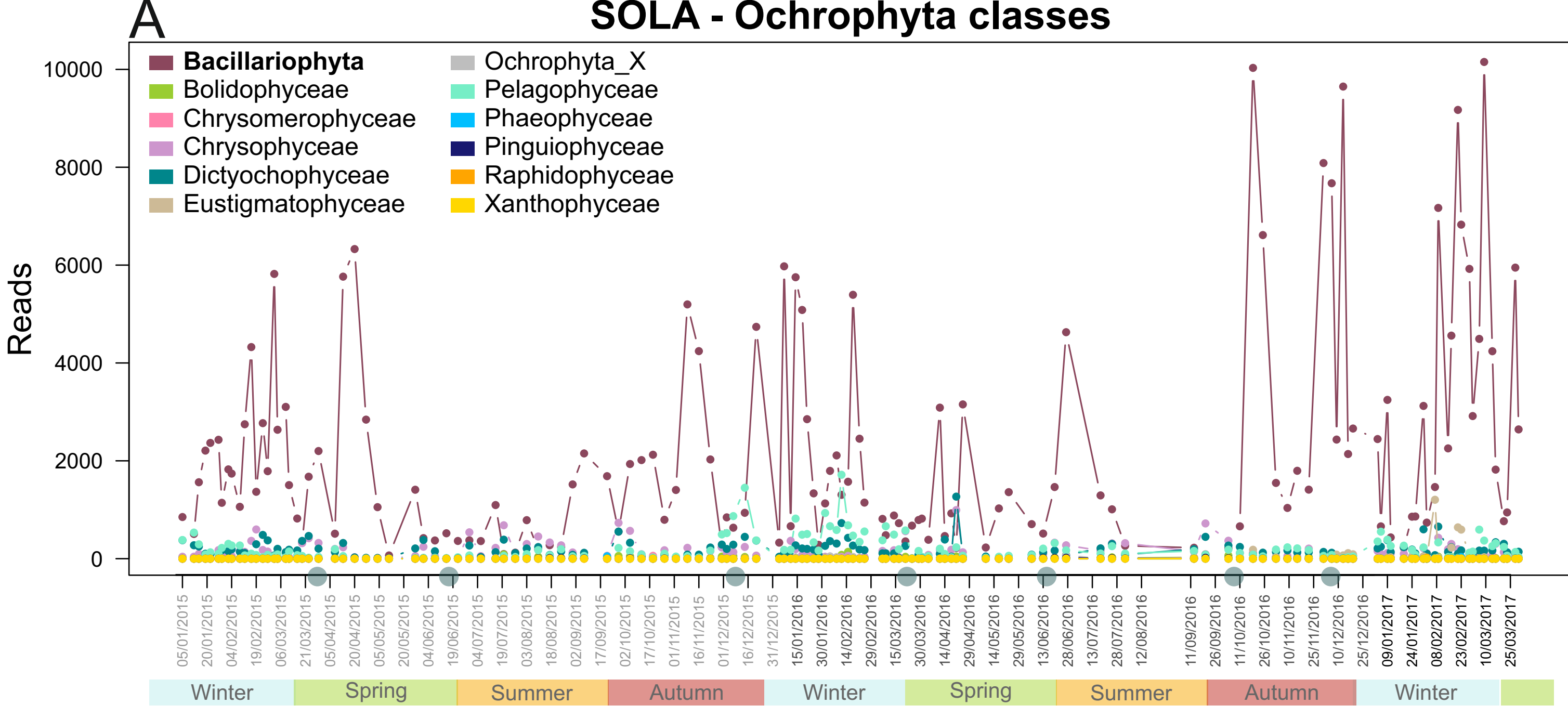

B

SOLA - Bacillariophyta divisions
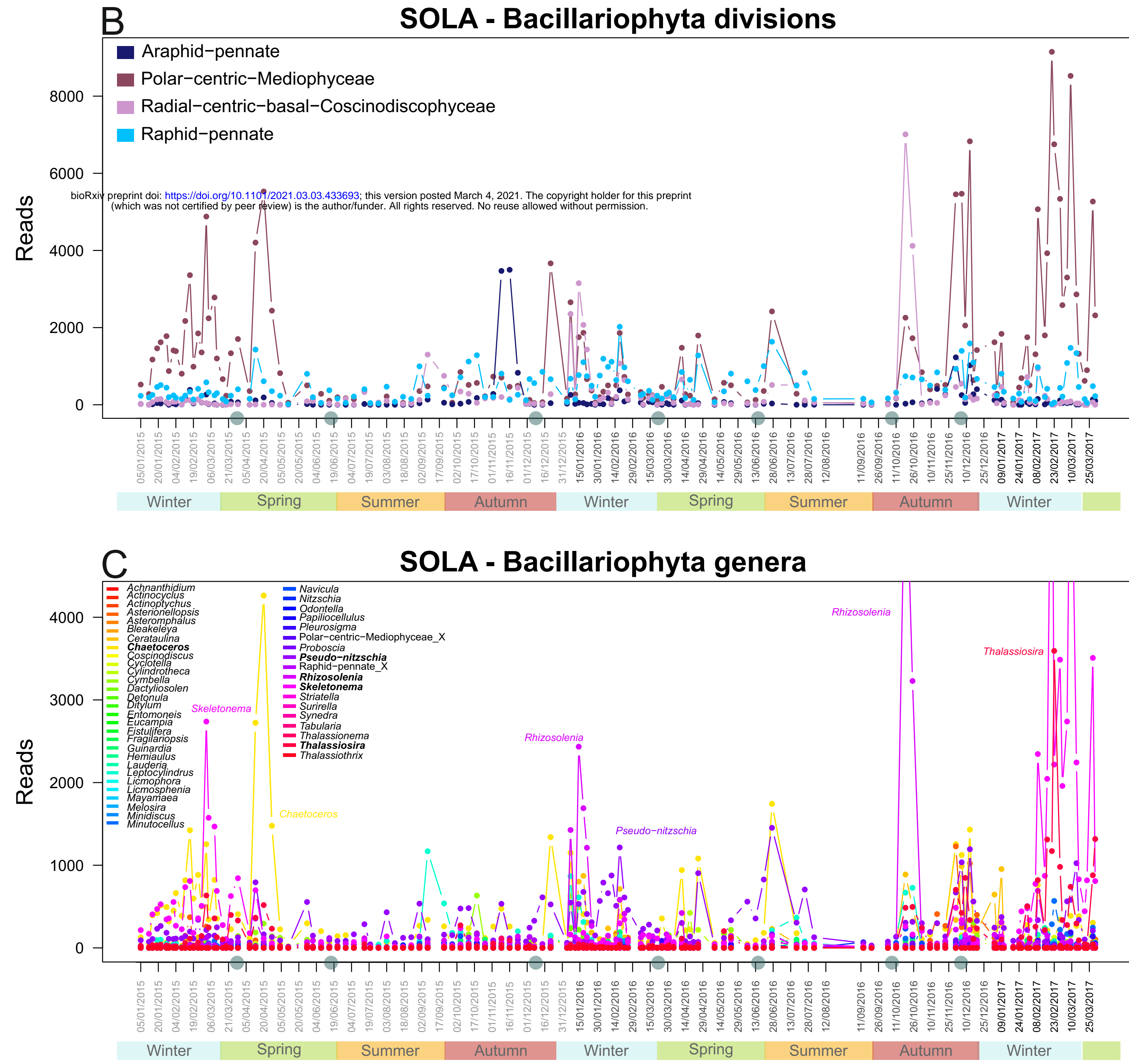

Supplementary Figure 3: Seasonal patterns of reads assigned to Ochrophyta microalgae (photosynthetic division of Stramenopiles) in SOLA environmental high-frequency time series. Grey dots correspond to the sampling dates of sea water for microcosms experiments. A- Pattern of abundance of the V4 metabarcodes assigned to Ochrophyta Classes. B- Pattern of abundance of V4 metabarcodes assigned to Bacillariophyta (Ochrophyta) families, C- Pattern of abundance of the numbers of the V4 metabarcodes assigned to the Bacillariophyta genera. The most abundant genera are in bold in the legend. 


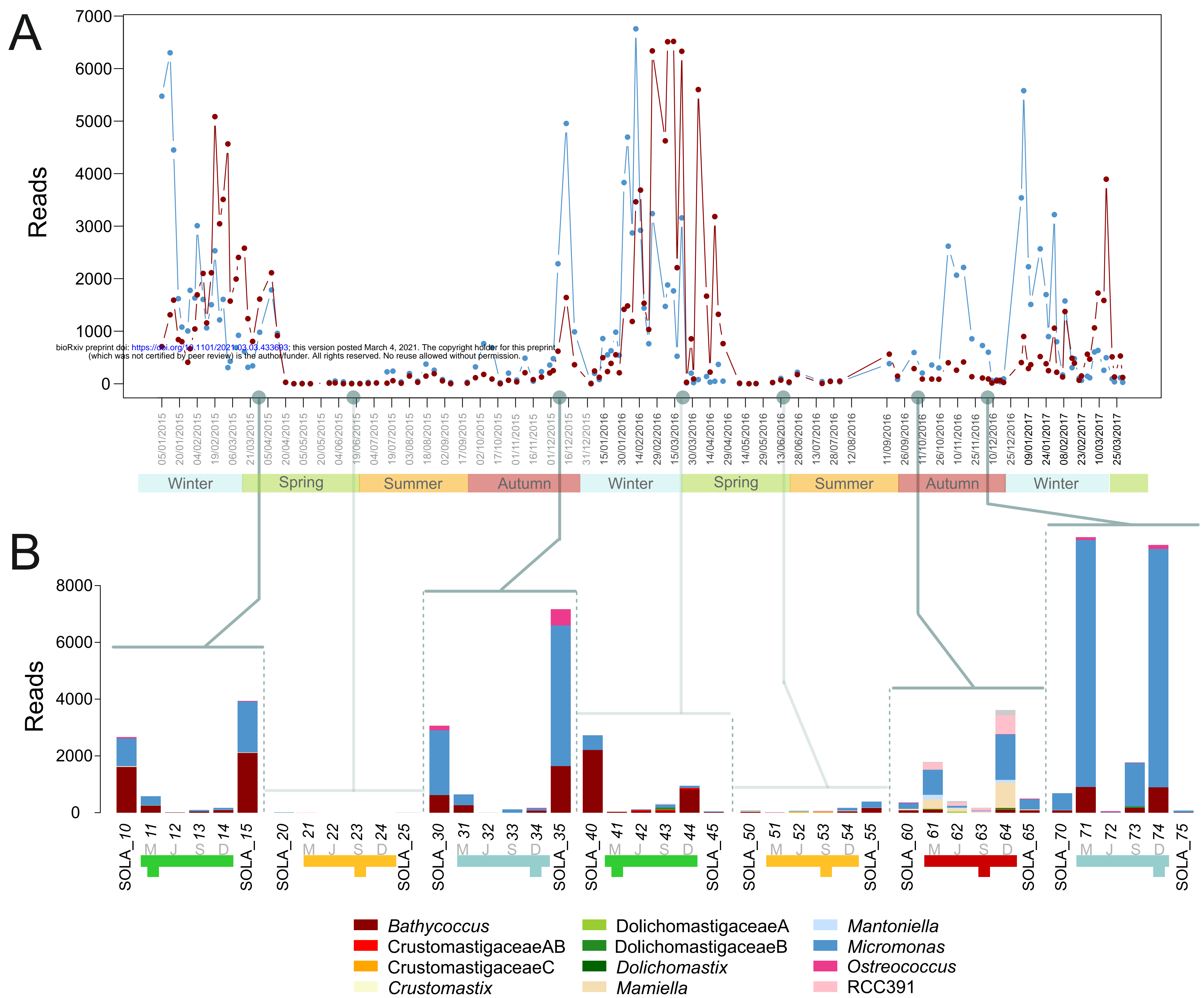

Supplementary Figure 4: Mamiellophyceae genera contribution in SOLA environmental time series and microcosms. A- Seasonal patterns of reads assigned to Mamiellophyceae genera at SOLA. Note that only the two most abundant genera Micromonas and Bathycoccus can be seen on the graph. Grey dots correspond to the sampling dates of sea water for microcosms experiments. B- Barplot representing the number of reads per Mamiellophyceae genera in 4 microcosm experiments and their associated natural sample. Colors in the barplot refer to Mamiellophyceae genera, colors in the legend correspond to the month, when the initial sea water was sample and letters (in grey) to the incubation conditions (i.e. artificial month): March (M), June (J), September (S) and December (D). 